\title{
A critical evaluation of quality of life in clinical trials of breast cancer patients treated with radiation therapy
}

\author{
Gustavo N. Marta ${ }^{1,2}$, Fabio Y. Moraes ${ }^{3}$, Elton T. T. Leite ${ }^{1,2}$, Edward Chow ${ }^{4}$, David Cella ${ }^{5}$, Andrew \\ Bottomley $^{6}$
}

${ }^{1}$ Department of Radiation Oncology, Hospital Sírio-Libanês, Sao Paulo, Brazil; ${ }^{2}$ Department of Radiology and Oncology of University of São Paulo, Radiation Oncology Unit, Instituto do Câncer do Estado de São Paulo (ICESP), Faculdade de Medicina da Universidade de São Paulo, Sao Paulo, Brazil; ${ }^{3}$ Radiation Medicine Program, Princess Margaret Cancer Centre, University Health Network, Toronto, ON, Canada; ${ }^{4}$ Sunnybrook Odette Cancer Centre, Sunnybrook Health Sciences Centre, University of Toronto, Toronto, Canada; ${ }^{5}$ Department of Medical Social Sciences,

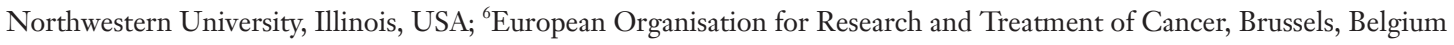

Contributions: (I) Conception and design: All authors; (II) Administrative support: All authors; (III) Provision of study materials or patients: GN Marta, FY Moraes, ET Leite; (IV) Collection and assembly of data: GN Marta, FY Moraes, ET Leite; (V) Data analysis and interpretation: All authors; (VI) Manuscript writing: All authors; (VII) Final approval of manuscript: All authors.

Correspondence to: Gustavo N. Marta. Department of Radiation Oncology, Hospital Sírio-Libanês, Rua Dona Adma Jafet, 91, Sao Paulo, SP 01308050, Brazil. Email: gustavo.marta@hc.fm.usp.br.

\begin{abstract}
The aim of this study was to investigate the extent to which health-related quality of life (HRQOL) parameters have been reported in phase III trials with breast cancer patients (BCPs) who received radiation therapy (RT). We also examine the frequency and correlates of significant HRQOL gains. A systematic review was conducted. When HRQOL was a study endpoint, we extracted data on the instruments used for HRQOL analysis, assessing if there was formal statistical comparison between study groups and the results of such comparisons as reported by the authors of the studies. In result, 182 trials were included. HRQOL was considered as endpoint in 38 (20.8\%) of the studies and it was used as primary endpoint in $10.9 \%$ of them. Of 22 trials that had a positive primary endpoint, 18 had a significant benefit in HRQOL, in favor of the experimental arm. Of 13 trials that had a negative primary endpoint, there were no differences in HRQOL among the study groups. With respect to HRQOL assessment, statistical methods and definition of timing of evaluation were described in 32 (84.2\%) and $36(94.7 \%)$ trials, respectively. In conclusion, HRQOL has been infrequently investigated in trials in BCP who received RT. Statistical methods and timing of evaluation were infrequently described with sufficient detail to be informative.
\end{abstract}

Keywords: Quality of life (QOL); breast cancer; treatment; radiation therapy (RT)

Submitted Sep 12, 2017. Accepted for publication Sep 17, 2017.

doi: 10.21037/apm.2017.09.06

View this article at: http://dx.doi.org/10.21037/apm.2017.09.06

\section{Introduction}

Worldwide, breast cancer is the most common cancer and the main cause of cancer-related death in women (1). In the United States, breast cancer is associated with 230,000 new cases and 40,000 deaths per year (2).

Radiation therapy (RT) is an important and validated modality for the management of breast cancer patients (BCPs) in all clinical stages. In ductal carcinoma patients, post-operative RT nearly duplicates local control (LC) rates, for both invasive and in situ recurrence (3). For patients who underwent breast-conserving surgery, postoperative whole breast irradiation (with or without regional nodal irradiation) is comparable regarding local regional control and overall survival (OS) when compared to radical mastectomy (RM) alone (4-10). Moreover, after RM, post-operative RT is prescribed for patients with locally advanced breast tumor and high-risk factors such as lymph node involvement, tumor size $>5 \mathrm{~cm}$ and/or positive surgical 
margins (11).

Despite the improvements in RT techniques, the treatment toxicities can harmfully affect patients' quality of life (QOL) $(12,13)$. In recent years, health care has progressively increased its interest in understanding healthrelated quality of life (HRQOL) as a crucial and meaningful endpoint, particularly in oncology (14). Usually, the primary objective of phase III randomized controlled clinical trial is to evaluate the effect of a selected intervention assessing clinical endpoints such as OS, disease-free survival (DFS) or progression-free survival (PFS), LC and treatment related toxicity (15). However, gradually more attention has been given to improving the patients' QOL throughout cancer treatment $(16,17)$. Although HRQOL assessment is important for clinical practice (18), the role of HRQOL records in supporting RT as a therapy for BCPs has not been formally measured yet.

The aim of this study was to investigate the magnitude to which QOL parameters have been reported in phase III studies on BCPs who received RT as part of the oncologic treatment, as well as the frequency and correlates of significant QOL gains.

\section{Methods}

A systematic review was performed. We restricted the search to phase III randomized clinical trials (RCTs) of patients with breast cancer. Eligible trials needed to have RT intervention as a main element of treatment in at least one of the arms. The electronic search was conducted with no publication year, no language or publication status restrictions. We searched the MEDLINE (1966 to September 2015) database (Table S1). We also screened the reference lists of relevant studies to ensure we had the maximum number of possible trials identified

\section{Selection of studies}

Two independent reviewers (GN Marta and ET Leite) assessed and selected the appropriate articles and the reference lists from these sources were searched for additional trials. Trials identified by the search were evaluated to determine whether they met the inclusion criteria. A third reviewer (FY Moraes) resolved discrepancies where they occurred.

\section{Collection of QOL data}

For each phase III RCT identified, the general trial features of the study and data on the use of endpoints were extracted according to the standardized checklist, including HRQOL parameters. With regard to HRQOL as an endpoint in the studies, we first attempted to identify any mention in the paper of HRQOL data collection during the trial, or, when no such mention was found, the existence of a companion paper dedicated to HRQOL analysis separately. When HRQOL was a study endpoint, we extracted information from the paper on the instruments used for HRQOL analysis, assessing if there was formal statistical comparison between study arms and the results of such comparisons as reported by the authors of the studies. We considered HRQOL as a positive endpoint when at least one of all parameters assessed had statistical significance.

The minimum standard checklist for evaluating HRQOL outcomes in cancer clinical trials (19) was applied. This instrument involves 11 critical issues that a study should report to produce consistent HRQOL results. HRQOL study is considered high-quality reporting when a minimum of 8 of the 11 conditions are present.

\section{Statistical analysis}

Summary statistics were used to describe absolute number and frequency of HRQOL-related issues and phase III RCT characteristics.

\section{Results}

The initial search retrieved 2,224 references. After screening of the titles and abstracts of these references, 1,819 studies were excluded and 405 full-text articles were selected. Of these, 271 publications, corresponding to 182 trials, fulfilled the eligibility criteria and were the subject of this analysis. Two independent reviewers selected appropriated articles and on which levels of discrepancies between the reviewers were very low (the third reviewer needed to solve discrepancies in $3 \%$ of the cases only). The flowchart of the retrieved studies and the characteristics of the included studies are presented in Figure 1 and Table 1, respectively. HRQOL was considered a formal endpoint in $38(20.8 \%)$ of the included studies (20-32) and it was used as primary endpoint in only $10.9 \%$ of them. OS, DFS or PFS, LC, local regional control was the primary endpoint for $102(55.8 \%)$ of the studies (33-44); toxicity was the primary endpoint for 44 (24.3\%) of the 182 trials. Most trials-153 $(84.0 \%$ ) - focused on biomedical intervention (for primary management and adjuvant treatment) (45-57). The same 


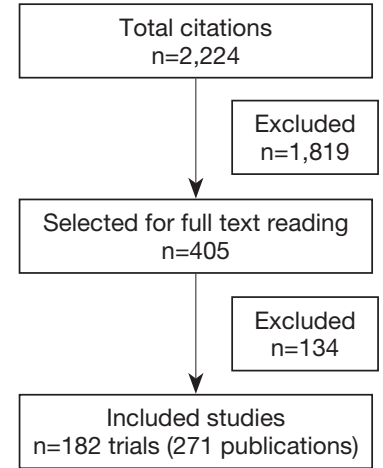

Figure 1 Flowchart of the process of study selection.

schedule of RT in all trial arms, with differences in other interventions, was the most common study.

Of 22 trials that had a positive primary endpoint, 18 reported significant benefit in HRQOL, in favor of the experimental arm. Of 13 trials that had a negative primary endpoint, there were no differences in HRQOL among the study groups (Tables 2,3). Statistical methods and definition of timing of evaluation were described for 32 and 36 trials with HRQOL assessment, respectively (Table 2).

Most HRQOL was assessed with tools common in HRQOL evaluation, with adequate psychometric properties; however, only $28 \%$ of the RCTs formally reported the tools' psychometric properties. The European Organisation for the Research and Treatment of Cancer Quality of Life Core Questionnaire (QLQ-C30, with or without BR23) was the most frequently used tool in 17 (44.7\%) of 38 studies. Eighteen trials $(47.4 \%)$ used two or more HRQOL assessment tools. The Functional Assessment of Cancer Therapy (FACT-General or -Breast specific) with or without additional measures was used in $9(23.6 \%)$ of 38 trials (Tables 2,4). Clinical significance and good quality data were shown in $51.4 \%$ and $48.6 \%$ of the RCTs with HRQOL as endpoint.

According to the minimum standard checklist for evaluating HRQOL outcomes, high-quality reporting was observed in $42.8 \%$ of trials. In Table 5 , we summarize the results of 11 issues that comprise essential elements of this classification.

\section{Discussion}

To the best of our knowledge, this is the first study to analyze the magnitude to which HRQOL parameters have been reported in phase III clinical trials in patients with
Table 1 Main characteristics of the 182 included randomized controlled trials of breast cancer and radiotherapy

\begin{tabular}{|c|c|c|}
\hline Characteristics & $\mathrm{N}$ & $\%$ \\
\hline \multicolumn{3}{|l|}{ Number of included patients } \\
\hline$\leq 100$ & 42 & 23.0 \\
\hline$>100$ to $<500$ & 74 & 40.7 \\
\hline$\geq 500$ to $<1,000$ & 36 & 19.8 \\
\hline$\geq 1,000$ & 30 & 16.5 \\
\hline \multicolumn{3}{|l|}{ Interventions arms } \\
\hline $\begin{array}{l}\text { Same radiation therapy in all study arms, with } \\
\text { differences in other interventions }\end{array}$ & 93 & 51.0 \\
\hline Different radiation therapy in study arms & 42 & 23.0 \\
\hline Groups differed by more than one intervention & 47 & 26.0 \\
\hline \multicolumn{3}{|l|}{ Intervention group* } \\
\hline Biomedical intervention & 153 & 84.0 \\
\hline Non-biomedical intervention & 29 & 16.0 \\
\hline \multicolumn{3}{|l|}{ Primary endpoint } \\
\hline Overall survival & 33 & 18.1 \\
\hline Disease-free or progression-free survival & 26 & 14.2 \\
\hline Local control & 38 & 20.8 \\
\hline Local regional control & 5 & 2.7 \\
\hline Toxicity & 44 & 24.3 \\
\hline Quality of life & 19 & 10.5 \\
\hline Other & 17 & 9.4 \\
\hline \multicolumn{3}{|l|}{ Quality of life as end point ${ }^{+}$} \\
\hline Yes & 38 & 20.8 \\
\hline No & 144 & 79.2 \\
\hline
\end{tabular}

*, type of intervention-articles were grouped based on to the category of intervention: biomedical intervention (for neoadjuvant, radical, adjuvant or palliative treatment) or nonbiomedical intervention (psychosocial intervention during the treatment); ${ }^{+}$, if the quality of life was formally considering as trial end point. $\mathrm{N}$, number of trials; \%, percentage.

breast cancer who underwent RT. Other authors previously assessed HRQOL issues in RCTs involving BCPs (58-61); however, the RT intervention was not necessarily performed and/or was not the focus on the articles.

After a confirmed diagnosis of breast cancer, the majority of patients underwent multimodality treatment (which includes surgery, RT and or systemic therapy). RT can 


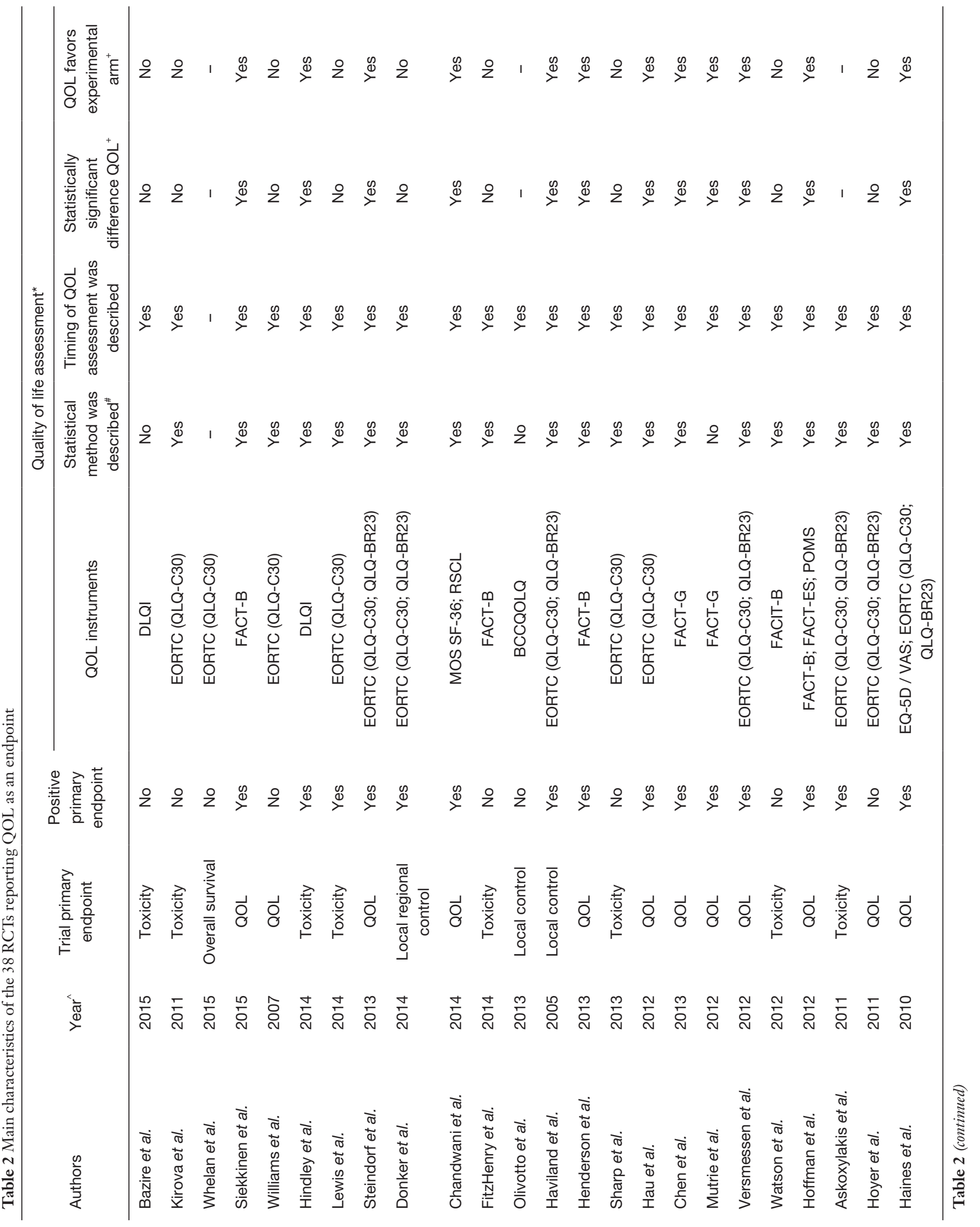




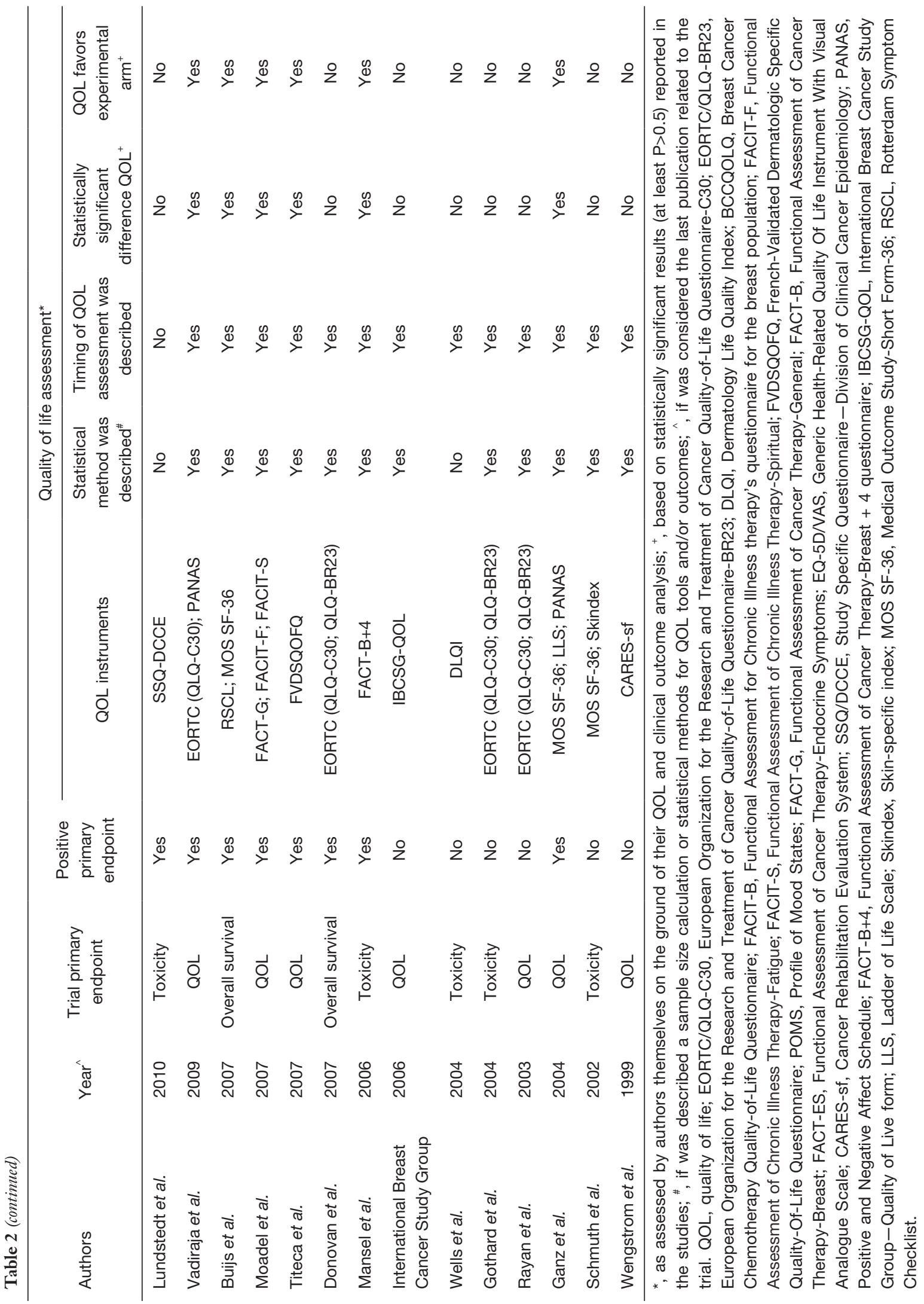


Table 3 Comparison of primary endpoints of the studies and QOL significant results

\begin{tabular}{lccc}
\hline Endpoint & $\begin{array}{c}\text { Benefit in QOL } \\
(\mathrm{n})\end{array}$ & No difference in QOL & Total (n) \\
\hline $\begin{array}{l}\text { Primary endpoint } \\
\text { positive* }\end{array}$ & 18 & 4 & 22 \\
$\begin{array}{l}\text { Primary endpoint } \\
\text { negative }^{*}\end{array}$ & 0 & 13 & 13 \\
\hline
\end{tabular}

*, if the primary endpoint of the trial was positive or negative based on statistically significant results (at least $P>0.5$ ) reported in the studies. n, number of trials; QOL, quality of life.

Table 4 Quality of QOL measurements

\begin{tabular}{lcc}
\hline Main QOL assessment tools & Number of trials & $\%$ \\
\hline EORTC QLQ-C30 alone & 6 & 15.7 \\
EORTC QLQ-C30 plus QLQ-BR23 & 9 & 23.7 \\
FACT-B alone & 4 & 10.5 \\
FACT-G alone & 2 & 5.2 \\
FACT-B plus additional measures & 1 & 2.7 \\
DLQI alone & 3 & 7.9 \\
Others & 13 & 34.3 \\
Studies using two or more QOL & 18 & 47.4 \\
assessment tools & & \\
\hline
\end{tabular}

QOL, quality of life.

cause acute and long-term adverse effects (AEs); however, higher-grade toxicities are relatively infrequent due to improvements in RT planning and delivery methods. Long-term AE, such as pneumonitis, cardiotoxicity and radiation-induced second malignancy can happen even many years after RT with important repercussions for the patients HRQOL (62). Thus, the evaluation of HRQOL is recognized as an essential element of the modern clinical oncological agenda, and HRQOL endpoints have been increasingly adopted in RCTs (17).

Overall, we demonstrated that HRQOL endpoints were used in $20.8 \%$ of RCTs in BCPs who receive RT. In most of the RCTs in which HRQOL were endpoints, formal methods comparisons between groups were described, although significant differences between groups were observed in 18 of 38 trials.

Currently, many instruments that aim at exploring HRQOL particularly in patients with breast cancer are available. The application of validated HRQOL tools
Table 5 Level of reporting according to the minimum standard checklist for evaluating QOL outcomes

\begin{tabular}{|c|c|c|}
\hline \multirow{2}{*}{ HRQOL issue } & \multicolumn{2}{|c|}{ Reports* } \\
\hline & $\mathrm{N}$ & $\%$ \\
\hline \multicolumn{3}{|l|}{ Conceptual } \\
\hline A priori hypothesis stated ${ }^{a}$ & 23 & 65.7 \\
\hline Rationale for instrument reported ${ }^{b}$ & 24 & 68.6 \\
\hline \multicolumn{3}{|l|}{ Measurement } \\
\hline Psychometric properties reported ${ }^{c}$ & 10 & 28.6 \\
\hline Cultural validity verified $^{d}$ & 13 & 37.2 \\
\hline Adequacy of domains covered ${ }^{e}$ & 24 & 68.6 \\
\hline \multicolumn{3}{|l|}{ Methodology } \\
\hline Instrument administration reported ${ }^{f}$ & 32 & 91.4 \\
\hline Baseline compliance reported $^{g}$ & 29 & 82.9 \\
\hline Timing of assessments documented ${ }^{\mathrm{h}}$ & 28 & 80.0 \\
\hline Missing data documented & 26 & 74.3 \\
\hline \multicolumn{3}{|l|}{ Interpretation } \\
\hline Clinical significance addressed ${ }^{j}$ & 18 & 51.4 \\
\hline Presentation of results in general' & 17 & 48.6 \\
\hline
\end{tabular}

*, all numbers and percentages represent the positive answers regarding the related topic of the checklist; " , if QOL end point and/or stated estimated changes due to the specific treatment were predefined; ${ }^{b}$, if rationale for using a specific QOL measure were defined; ${ }^{c}$, if previously validated measure was used or psychometric properties were described; ${ }^{d}$, if the measure for the particular study population was validated; ' , if the main QOL measurements important for a generic cancer population and/or according to the specific research issue were assessed; ${ }^{f}$, if who and/or in which clinical setting the QOL instrument was managed; ${ }^{g}$, if the number of patients providing a QOL assessment before the beginning of treatment was informed; ${ }^{h}$, if the HRQOL timing of assessment during the study was defined; ', if the details on QOL missing data during the trial was mentioned; ${ }^{j}$, if the QOL data being clinically significant from a patient's view and not only statistically significant; ', if the QOL outcomes, giving any comments in regard of the results were performed for the authors. $\mathrm{N}$, number of articles reporting item/number of articles to which item is applicable; QOL, quality of life.

might enable better understanding of the side effects of breast cancer treatment and their true consequences for the patients. As presented in Tables 2 and 4, all included trials used a validated HRQOL instrument whereupon most widely used tools were EORTC (QLQ-C30 and QLQBR23) followed by FACT-B (Table 4). Similar findings 
were demonstrated by other authors (58). These results propose that EORTC (QLQ-C30 and QLQ-BR23) and FACT-B instruments are considered by investigators to be the standard assessment for the breast cancer trials setting, although there was no specific justification for the HRQOL instrument selection. This trend poses significant consequences, since the selection of HRQOL tools should encompass at least 3 fundamental elements (reporting, analysis and interpretation) of HRQOL data research. Formal explanation was not present in almost all RCTs, and its absence was often associated with the lack of a predefined HRQOL hypothesis.

Despite our study being a combined evaluation of all HRQOL instruments, a formal assessment of the tools used or HRQOL elements reported was performed (Table 5). This is a robust evaluation of HRQOL results in breast cancer that can potentially offer critical data regarding reporting, analyzing and interpreting of HRQOL literature.

It is important to recognize that we did not apply CONSORT-PRO (63) to evaluate the included RCTs in this study. CONSORT-PRO is a recent development that took the checklist and others into account. If we applied the CONSORT-PRO to the present data, we would be assessing studies on criteria that were not formally recommended until 2013. In this context, one of the limitations of our study is that we did not review the quality of the included RCTs. In fact, we reviewed the quality of the publications and in doing so understood that space limitations in journals may have meant that the authors were not able to report things in as much detail as they may have wished. Some other limitations are that we have not reviewed if HRQOL assessment was expected in the RCT's published protocol, nor if the applied HRQOL instrument had a proven validity for the specific population of each RCT. However, our study permits a comprehensive overview of HRQOL research in BCPs who receive RT as part of their treatment. This is an important issue that was also demonstrated for other authors in different scenarios such as locally advanced/metastatic breast cancer and melanoma.

In conclusion, our analysis shows that HRQOL has been infrequently investigated in RCT in BCPs who received RT. Statistical methods and timing of evaluation were frequently described with enough detail to be informative and applicable. However, significant benefit in HRQOL was frequently reported when a positive primary outcome was reported, showing that QOL can be an important predictor of better treatment outcomes.

\section{Acknowledgements}

None.

\section{Footnote}

Conflicts of Interest: The authors have no conflicts of interest to declare.

\section{References}

1. Globocan 2012. Fast Stats. Most frequent cancers: both sexes. Available online: http://globocan.iarc.fr/Default. aspx. Accessed on December 05, 2013.

2. Siegel R, Naishadham D, Jemal A. Cancer statistics, 2013. CA Cancer J Clin 2013;63:11-30.

3. Cutuli B, Bernier J, Poortmans P. Radiotherapy in DCIS, an underestimated benefit? Radiother Oncol 2014;112:1-8.

4. van Dongen JA, Bartelink H, Fentiman IS, et al. Randomized clinical trial to assess the value of breastconserving therapy in stage I and II breast cancer, EORTC 10801 trial. J Natl Cancer Inst Monogr 1992;(11):15-8.

5. Jacobson JA, Danforth DN, Cowan KH, et al. Ten-year results of a comparison of conservation with mastectomy in the treatment of stage I and II breast cancer. N Engl J Med 1995;332:907-11.

6. Blichert-Toft M, Rose C, Andersen JA, et al. Danish randomized trial comparing breast conservation therapy with mastectomy: six years of life-table analysis. Danish Breast Cancer Cooperative Group. J Natl Cancer Inst Monogr 1992;(11):19-25.

7. Veronesi U, Saccozzi R, Del Vecchio M, et al. Comparing radical mastectomy with quadrantectomy, axillary dissection, and radiotherapy in patients with small cancers of the breast. N Engl J Med 1981;305:6-11.

8. Fisher B, Anderson S, Bryant J, et al. Twenty-year followup of a randomized trial comparing total mastectomy, lumpectomy, and lumpectomy plus irradiation for the treatment of invasive breast cancer. N Engl J Med 2002;347:1233-41.

9. Veronesi U, Cascinelli N, Mariani L, et al. Twentyyear follow-up of a randomized study comparing breastconserving surgery with radical mastectomy for early breast cancer. N Engl J Med 2002;347:1227-32.

10. Marta GN, Hanna SA, Martella E, et al. Early stage breast cancer and radiotherapy: update. Rev Assoc Med Bras (1992) 2011;57:459-64.

11. EBCTCG (Early Breast Cancer Trialists' Collaborative 
Group), McGale P, Taylor C, et al. Effect of radiotherapy after mastectomy and axillary surgery on 10-year recurrence and 20-year breast cancer mortality: metaanalysis of individual patient data for 8135 women in 22 randomised trials. Lancet 2014;383:2127-35.

12. Sociedade Brasileira de Radioterapia, Marta GN, Hanna $\mathrm{SA}$, et al. Treatment with intensity-modulated radiation therapy (IMRT) for breast cancer. Rev Assoc Med Bras (1992) 2014;60:508-11.

13. Marta GN, Hanna SA, Martella E, et al. Complications from radiotherapy for breast cancer. Sao Paulo Med J 2011;129:116-7.

14. Michael M, Tannock IF. Measuring health-related quality of life in clinical trials that evaluate the role of chemotherapy in cancer treatment. CMAJ 1998;158:1727-34.

15. Leite ETT, Moraes FY, Marta GN, et al. Trial sponsorship and self-reported conflicts of interest in breast cancer radiation therapy: An analysis of prospective clinical trials. Breast 2017;33:29-33.

16. Minasian LM, O'Mara AM, Reeve BB, et al. Healthrelated quality of life and symptom management research sponsored by the National Cancer Institute. J Clin Oncol 2007;25:5128-32.

17. Bottomley A, Aaronson NK; European Organisation for Research and Treatment of Cancer. International perspective on health-related quality-of-life research in cancer clinical trials: the European Organisation for Research and Treatment of Cancer experience. J Clin Oncol 2007;25:5082-6.

18. Bottomley A, Pe M, Sloan J, et al. Analysing data from patient-reported outcome and quality of life endpoints for cancer clinical trials: a start in setting international standards. Lancet Oncol 2016;17:e510-4.

19. Efficace F, Bottomley A, Osoba D, et al. Beyond the development of health-related quality-of-life (HRQOL) measures: a checklist for evaluating HRQOL outcomes in cancer clinical trials--does HRQOL evaluation in prostate cancer research inform clinical decision making? J Clin Oncol 2003;21:3502-11.

20. Bazire L, Fromantin I, Diallo A, et al. Hydrosorb® versus control (water based spray) in the management of radioinduced skin toxicity: Results of multicentre controlled randomized trial. Radiother Oncol 2015;117:229-33.

21. Kirova YM, Fromantin I, De Rycke Y, et al. Can we decrease the skin reaction in breast cancer patients using hyaluronic acid during radiation therapy? Results of phase III randomised trial. Radiother Oncol 2011;100:205-9.
22. Whelan TJ, Olivotto IA, Parulekar WR, et al. Regional Nodal Irradiation in Early-Stage Breast Cancer. N Engl J Med 2015;373:307-16.

23. Siekkinen M, Pyrhönen S, Ryhänen A, et al. Psychosocial outcomes of e-feedback of radiotherapy for breast cancer patients: a randomized controlled trial. Psychooncology 2015;24:515-22.

24. Williams LJ, Kunkler IH, King CC, et al. A randomised controlled trial of post-operative radiotherapy following breast-conserving surgery in a minimum-risk population. Quality of life at 5 years in the PRIME trial. Health Technol Assess 2011;15:i-xi,1-57.

25. Hindley A, Zain Z, Wood L, et al. Mometasone furoate cream reduces acute radiation dermatitis in patients receiving breast radiation therapy: results of a randomized trial. Int J Radiat Oncol Biol Phys 2014;90:748-55.

26. Lewis L, Carson S, Bydder S, et al. Evaluating the effects of aluminum-containing and non-aluminum containing deodorants on axillary skin toxicity during radiation therapy for breast cancer: a 3-armed randomized controlled trial. Int J Radiat Oncol Biol Phys 2014;90:765-71.

27. Steindorf K, Schmidt ME, Klassen O, et al. Randomized, controlled trial of resistance training in breast cancer patients receiving adjuvant radiotherapy: results on cancer-related fatigue and quality of life. Ann Oncol 2014;25:2237-43

28. Donker M, van Tienhoven G, Straver ME, et al. Radiotherapy or surgery of the axilla after a positive sentinel node in breast cancer (EORTC 10981-22023 AMAROS): a randomised, multicentre, open-label, phase 3 non-inferiority trial. Lancet Oncol 2014;15:1303-10.

29. Chandwani KD, Perkins G, Nagendra HR, et al. Randomized, controlled trial of yoga in women with breast cancer undergoing radiotherapy. J Clin Oncol 2014;32:1058-65.

30. FitzHenry F, Wells N, Slater V, et al. A randomized placebo-controlled pilot study of the impact of healing touch on fatigue in breast cancer patients undergoing radiation therapy. Integr Cancer Ther 2014;13:105-13.

31. Olivotto IA, Whelan TJ, Parpia S, et al. Interim cosmetic and toxicity results from RAPID: a randomized trial of accelerated partial breast irradiation using threedimensional conformal external beam radiation therapy. J Clin Oncol 2013;31:4038-45.

32. Haviland JS, Owen JR, Dewar JA, et al. The UK standardisation of breast radiotherapy (START) trials of radiotherapy hypofractionation for treatment of early 
breast cancer: 10-year follow-up results of two randomised controlled trials. Lancet Oncol 2013;14:1086-94.

33. Henderson VP, Massion AO, Clemow L, et al. A randomized controlled trial of mindfulness-based stress reduction for women with early-stage breast cancer receiving radiotherapy. Integr Cancer Ther 2013;12:404-13.

34. Sharp L, Finnilä K, Johansson H, et al. No differences between Calendula cream and aqueous cream in the prevention of acute radiation skin reactions--results from a randomised blinded trial. Eur J Oncol Nurs 2013;17:429-35.

35. Hau E, Browne L, Capp A, et al. The impact of breast cosmetic and functional outcomes on quality of life: long-term results from the St. George and Wollongong randomized breast boost trial. Breast Cancer Res Treat 2013;139:115-23.

36. Chen Z, Meng Z, Milbury K, et al. Qigong improves quality of life in women undergoing radiotherapy for breast cancer: results of a randomized controlled trial. Cancer 2013;119:1690-8.

37. Mutrie N, Campbell A, Barry S, et al. Five-year followup of participants in a randomised controlled trial showing benefits from exercise for breast cancer survivors during adjuvant treatment. Are there lasting effects? J Cancer Surviv 2012;6:420-30.

38. Versmessen H, Vinh-Hung V, Van Parijs H, et al. Healthrelated quality of life in survivors of stage I-II breast cancer: randomized trial of post-operative conventional radiotherapy and hypofractionated tomotherapy. BMC Cancer 2012;12:495.

39. Watson LC, Gies D, Thompson E, et al. Randomized control trial: evaluating aluminum-based antiperspirant use, axilla skin toxicity, and reported quality of life in women receiving external beam radiotherapy for treatment of Stage 0, I, and II breast cancer. Int J Radiat Oncol Biol Phys 2012;83:e29-34.

40. Hoffman CJ, Ersser SJ, Hopkinson JB, et al. Effectiveness of mindfulness-based stress reduction in mood, breast- and endocrine-related quality of life, and well-being in stage 0 to III breast cancer: a randomized, controlled trial. J Clin Oncol 2012;30:1335-42.

41. Askoxylakis V, Jensen AD, Häfner MF, et al. Simultaneous integrated boost for adjuvant treatment of breast cancer-intensity modulated vs. conventional radiotherapy: the IMRT-MC2 trial. BMC Cancer 2011;11:249.

42. Hoyer BB, Toft GV, Debess J, et al. A nurse-led telephone session and quality of life after radiotherapy among women with breast cancer: a randomized trial. Open Nurs J
2011;5:31-7.

43. Haines TP, Sinnamon P, Wetzig NG, et al. Multimodal exercise improves quality of life of women being treated for breast cancer, but at what cost? Randomized trial with economic evaluation. Breast Cancer Res Treat 2010;124:163-75.

44. Lundstedt D, Gustafsson M, Malmstrom P, et al. Symptoms 10-17 years after breast cancer radiotherapy data from the randomised SWEBCG91-RT trial. Radiother Oncol 2010;97:281-7.

45. Vadiraja HS, Rao MR, Nagarathna R, et al. Effects of yoga program on quality of life and affect in early breast cancer patients undergoing adjuvant radiotherapy: a randomized controlled trial. Complement Ther Med 2009;17:274-80.

46. Buijs C, Rodenhuis S, Seynaeve CM, et al. Prospective study of long-term impact of adjuvant high-dose and conventional-dose chemotherapy on health-related quality of life. J Clin Oncol 2007;25:5403-9.

47. Moadel AB, Shah C, Wylie-Rosett J, et al. Randomized controlled trial of yoga among a multiethnic sample of breast cancer patients: effects on quality of life. J Clin Oncol 2007;25:4387-95.

48. Titeca G, Poot F, Cassart D, et al. Impact of cosmetic care on quality of life in breast cancer patients during chemotherapy and radiotherapy: an initial randomized controlled study. J Eur Acad Dermatol Venereol 2007;21:771-6.

49. Donovan E, Bleakley N, Denholm E, et al. Randomised trial of standard 2D radiotherapy (RT) versus intensity modulated radiotherapy (IMRT) in patients prescribed breast radiotherapy. Radiother Oncol 2007;82:254-64.

50. Mansel RE, Fallowfield L, Kissin M, et al. Randomized multicenter trial of sentinel node biopsy versus standard axillary treatment in operable breast cancer: the ALMANAC Trial. J Natl Cancer Inst 2006;98:599-609.

51. International Breast Cancer Study Group, Rudenstam $\mathrm{CM}$, Zahrieh D, et al. Randomized trial comparing axillary clearance versus no axillary clearance in older patients with breast cancer: first results of International Breast Cancer Study Group Trial 10-93. J Clin Oncol 2006;24:337-44.

52. Wells M, Macmillan M, Raab G, et al. Does aqueous or sucralfate cream affect the severity of erythematous radiation skin reactions? A randomised controlled trial. Radiother Oncol 2004;73:153-62.

53. Gothard L, Cornes P, Earl J, et al. Double-blind placebocontrolled randomised trial of vitamin $\mathrm{E}$ and pentoxifylline in patients with chronic arm lymphoedema and fibrosis after surgery and radiotherapy for breast cancer. Radiother 
Oncol 2004;73:133-9.

54. Rayan G, Dawson LA, Bezjak A, et al. Prospective comparison of breast pain in patients participating in a randomized trial of breast-conserving surgery and tamoxifen with or without radiotherapy. Int J Radiat Oncol Biol Phys 2003;55:154-61.

55. Ganz PA, Kwan L, Stanton AL, et al. Quality of life at the end of primary treatment of breast cancer: first results from the moving beyond cancer randomized trial. J Natl Cancer Inst 2004;96:376-87.

56. Schmuth M, Wimmer MA, Hofer S, et al. Topical corticosteroid therapy for acute radiation dermatitis: a prospective, randomized, double-blind study. Br J Dermatol 2002;146:983-91.

57. Wengström Y, Häggmark C, Strander H, et al. Effects of a nursing intervention on subjective distress, side effects and quality of life of breast cancer patients receiving curative radiation therapy--a randomized study. Acta Oncol 1999;38:763-70.

58. Ghislain I, Zikos E, Coens C, et al. Health-related quality of life in locally advanced and metastatic breast

Cite this article as: Marta GN, Moraes FY, Leite E, Chow E, Cella D, Bottomley A. Healing, spirituality and integrative medicine. Ann Palliat Med 2017;6(Suppl 2):S223-S232. doi: 10.21037/apm.2017.09.06 cancer: methodological and clinical issues in randomised controlled trials. Lancet Oncol 2016;17:e294-304.

59. Lemieux J, Goodwin PJ, Bordeleau LJ, et al. Quality-oflife measurement in randomized clinical trials in breast cancer: an updated systematic review (2001-2009). J Natl Cancer Inst 2011;103:178-231.

60. Meyer F, Fortin A, Gélinas M, et al. Health-related quality of life as a survival predictor for patients with localized head and neck cancer treated with radiation therapy. J Clin Oncol 2009;27:2970-6.

61. Adamowicz K, Jassem J, Katz A, et al. Assessment of quality of life in advanced breast cancer. An overview of randomized phase III trials. Cancer Treat Rev 2012;38:554-8.

62. Meric F, Buchholz TA, Mirza NQ, et al. Long-term complications associated with breast-conservation surgery and radiotherapy. Ann Surg Oncol 2002;9:543-9.

63. Calvert M, Blazeby J, Altman DG, et al. Reporting of patient-reported outcomes in randomized trials: the CONSORT PRO extension. JAMA 2013;309:814-22. 
Supplementary

Table S1 Search strategy used for MEDLINE

\begin{tabular}{ll}
\hline Database & Search strategy \\
\hline Medline (via PubMed), & ("Breast Neoplasms”[Mesh] OR Breast Neoplasm OR Neoplasm, Breast OR Neoplasms, Breast OR Tumors, \\
09/29/2015 & Breast OR Breast Tumors OR Breast Tumor OR Tumor, Breast OR Mammary Neoplasms, Human OR Human \\
& Mammary Neoplasm OR Human Mammary Neoplasms OR Neoplasm, Human Mammary OR Neoplasms, Human \\
& Mammary OR Mammary Neoplasm, Human OR Mammary Carcinoma, Human OR Carcinoma, Human Mammary \\
& OR Carcinomas, Human Mammary OR Human Mammary Carcinomas OR Mammary Carcinomas, Human OR \\
& Human Mammary Carcinoma OR Breast Cancer OR Cancer, Breast OR Cancer of Breast OR Mammary Cancer OR \\
& Malignant Neoplasm of Breast OR Malignant Tumor of Breast OR Breast Carcinoma OR Cancer of the Breast) AND \\
& ("Radiotherapy"[Mesh] OR Radiotherapies OR Radiotherapy, Targeted OR Radiotherapies, Targeted OR Targeted \\
& Radiotherapies OR Targeted Radiotherapy) AND (Clinical Trial[ptyp]) \\
\hline
\end{tabular}

